\title{
Atividade antimicrobiana e antioxidante de filmes comestíveis de gelatina e quitosana adicionados de óleos essenciais
}

\author{
Marcella Vitoria Galindo ${ }^{1}$, Isabela dos Santos Paglione ${ }^{2}$, Geane Cristiane Balan ${ }^{3}$, Lyssa Setsuko \\ Sakanaka $^{4}$, Marianne Ayumi Shirai ${ }^{5}$
}

Os óleos essenciais têm sido reconhecidos por suas propriedades antimicrobiana e antioxidante, ganhando destaque na indústria de alimentos para ser utilizado como aditivo natural. Entretanto, a adição direta de óleos essenciais na formulação de alimentos pode provocar a perda de sua bioatividade em razão das condições de processo (luz, calor, pressão e presença de oxigênio) empregadas. Neste sentido, a incorporação de óleos essenciais em filmes comestíveis é uma interessante alternativa, permitindo a obtenção de embalagens ativas que auxiliam na conservação de alimentos. Neste trabalho, filmes comestíveis de gelatina e quitosana adicionados de óleo essencial de alecrim e orégano foram produzidos. Nos filmes obtidos foram avaliadas as propriedades mecânicas, a morfologia por microscopia eletrônica de varredura, a atividade antimicrobiana frente aos microrganismos Escherichia coli e Staphylococcus aureus, o conteúdo de compostos fenólicos totais e a atividade antioxidante pelos métodos ABTS e DPPH. Os filmes contendo óleos essenciais apresentaram atividade antimicrobiana e antioxidante, sendo em maior proporção para o filme com óleo essencial de orégano, e maior resistência à perfuração. A adição de óleos essenciais não alterou a morfologia dos filmes, a qual apresentou-se compacta, homogênea e sem separação aparente de fases. Os filmes obtidos possuem potencial para produção de embalagens ativas biodegradáveis com o propósito de auxiliar na segurança microbiológica, nutricional e sensorial dos alimentos.

Palavras-chave: Óleo essencial de orégano. Óleo essencial de alecrim. Propriedades mecânicas. Compostos bioativos.

\section{Antimicrobial and antioxidant activity of chitosan/gelatin and essential oil edible film}

Essential oils have been recognized for their antimicrobial and antioxidant properties, gaining importance in the food industry to be used as a natural additive. However, the direct addition of essential oils in the food formulation can cause the loss of their bioactivity due to the process conditions (light, heat, pressure and presence of oxygen) employed. In this sense, the incorporation of essential oils into edible films is an interesting alternative, allowing to obtaining active packaging that helps in the food conservation. In this work, edible films of gelatin and chitosan added with essential oil of rosemary and oregano were produced. In the obtained films were evaluated the mechanical properties, morphology, the antimicrobial activity against Escherichia coli and Staphylococcus aureus, the

${ }_{1}^{1}$ Departamento Acadêmico de Alimentos. Universidade Tecnológica Federal do Paraná (UTFPR). Londrina. Paraná. Brasil. E-mail: rpmarcella@hotmail.com.

2 Programa de Pós-graduação em Tecnologia de Alimentos. Universidade Tecnológica Federal do Paraná (UTFPR).Londrina. Paraná. Brasil. E-mail: isabela_paglione@hotmail.com

3 Programa de Pós-graduação em Tecnologia de Alimentos. Universidade Tecnológica Federal do Paraná (UTFPR). Londrina. Paraná. Brasil. E-mail: geanebalan@gmail.com

4 Programa de Pós-graduação em Tecnologia de Alimentos. Universidade Tecnológica Federal do Paraná (UTFPR). Londrina. Paraná. Brasil. E-mail: lyssa@utfpr.edu.br

5 Programa de Pós-graduação em Tecnologia de Alimentos. Universidade Tecnológica Federal do Paraná (UTFPR). Londrina. Paraná. Brasil. E-mail: marianneshirai@utfpr.edu.br. Endereço para correspondência: Avenida dos Pioneiros, 3131 - Jardim Morumbi - Londrina - PR, CEP 86036-370. Tel. (43) 3315-6153 
content of total phenolic compounds, and the antioxidant activity by the ABTS and DPPH methods. The films containing essential oils presented antimicrobial and antioxidant activity, being in greater proportion in the film with essential oil of oregano, and greater puncture resistance. The addition of essential oils did not alter the morphology of the films, which was compact, homogeneous and without apparent separation of phases. The films obtained have potential for the production of biodegradable active packaging in order to assist in microbiological, nutritional and sensorial food safety.

Keywords: Oregano essential oil. Rosemary essential oil. Mechanical properties. Bioactive compounds.

\section{INTRODUÇÃO}

Óleos essenciais são líquidos oleosos aromáticos, extraídos de diferentes partes de plantas (flores, botões, sementes, folhas, galhos, casca, frutas e raízes). Quimicamente, são constituídos de diferentes componentes como terpenos e seus derivados (carvacrol, timol, eugenol, terpineno, linalol e carvona), aldeídos, cetonas, álcoois e fenóis, e se destacam por apresentarem amplo espectro de atividade biológica (antibacteriano, antifúngico, antiviral, controle de pragas e repelentes de insetos) e antioxidantes $^{[1,2,3,4,5]}$.

Os óleos essenciais se destacam como um ingrediente natural para a indústria de alimentos, sobretudo por apresentarem sabor e aroma intensos. A adição direta em alimentos deve ser cautelosa para não afetar as propriedades sensoriais. Desta forma, seu uso é de grande interesse na produção de filmes comestíveis biodegradáveis, visando a obtenção de uma embalagem ativa que auxilia na melhoria na qualidade sensorial, nutricional e microbiológica dos alimentos ${ }^{[6,7,8]}$.

Dentre os biopolímeros utilizados como matéria-prima na produção de filmes, a gelatina se destaca pela sua abundância e por ser amplamente utilizado na área farmacêutica e de alimentos. É obtida a partir da desnaturação do colágeno, que é o principal constituinte de ossos e pele de bovinos, suínos e pescados ${ }^{[9]}$. Entretanto, sua utilização é restrita pelo caráter hidrofílico e assim apresentar baixa barreira ao vapor de água ${ }^{[10]}$.
Uma maneira de melhorar as propriedades hidrofílicas da gelatina é realizar blendas com outros biopolímeros, como a quitosana, que é obtida a partir da desacetilação da quitina. A quitina é o segundo maior carboidrato existente no planeta e é encontrada em carapaças de crustáceos (caranguejo, lagosta e camarões) e insetos, podendo ser produzida também por fungos ${ }^{[11,12]}$.

Diversos estudos relatam com sucesso a incorporação de óleos essenciais de orégano (Origanum vulgare L.) e de alecrim (Rosmarinus officinalis L.) em filmes comestíveis ${ }^{[7,}$ 9, ${ }^{13}$. Hosseini et al. ${ }^{[14]}$ verificaram que filmes de gelatina e quitosana contendo óleo essencial de orégano apresentaram atividade antimicrobiana frente a microrganismos Gram positivos (Staphylococcus aureus e Listeria monocytogenes) e Gram negativos (Salmonella Enteritidis e Escherichia coli). Entretanto, os autores não avaliaram a atividade antioxidante dos filmes obtidos. Bonilla e Sobral ${ }^{[13]}$ produziram filmes de gelatina e quitosana com extrato alcoólico de alecrim, canela, boldo e guaraná e observaram significativa atividade antioxidante e atividade antimicrobiana frente a Staphylococcus aureus e Escherichia coli.

O objetivo deste trabalho foi produzir filmes comestíveis de gelatina e quitosana adicionados de óleo essencial de orégano e alecrim e avaliar as propriedades mecânicas, atividades antimicrobiana e antioxidante e morfologia, visando a obtenção de uma 
embalagem ativa biodegradável para auxiliar na segurança alimentar e nutricional.

\section{MATERIAL E MÉTODOS}

\section{Material}

Para a produção dos filmes, utilizou-se quitosana de baixa massa molar (Sigma Aldrich, EUA) com grau de desacetilação de 85\%, gelatina tipo B com bloom 250 (Gelita do Brasil, Brasil), glicerol (Dinâmica, Brasil), óleo essencial de alecrim (Ferquima, Brasil), óleo essencial de orégano (Quinarí, Brasil) e tween 80 (Anidrol, Brasil). Para a realização das análises antimicrobianas utilizou-se Ágar Müeller Hinton (Himedia, India), caldo Müeller Hinton (Himedia, India) e Peptona Bacteriológica (Himedia, India). Para a análise de antioxidante e compostos fenólicos totais utilizou-se 2,2-difenil-1-picrilhidrazil (DPPH), 6-Hidroxi-2,5,7,8-tetrametilchroman-2-ácido carboxílico (Trolox), ABTS (2,2'-azinobis [3ethylbenzothiazoline-6-sulfonic acid] diammonium salt), persulfato de potássio, ácido gálico e reagente de Folin-Ciocalteu todos da Sigma Aldrich, EUA.

\section{Produção dos filmes comestíves de gelatina e quitosana adicionados de óleos essenciais}

Os filmes foram preparados pela técnica de casting conforme Bonilla e Sobral ${ }^{[13]}$, com algumas modificações. Inicialmente preparou-se as soluções de gelatina e quitosana separadamente. A quitosana $2 \%(\mathrm{~m} / \mathrm{v})$ foi dissolvida em ácido acético $1 \%$ (v/v) e mantida sob agitação magnética com aquecimento a $45^{\circ} \mathrm{C}$ por 1 hora. A solução de gelatina (GEL) $4 \%(\mathrm{p} / \mathrm{v})$ com adição de glicerol $(1 \mathrm{~g} / 100 \mathrm{~mL}$ de solução de gelatina) foi dissolvida sob agitação magnética e aquecimento a $55^{\circ} \mathrm{C}$ por 35 min. Posteriormente, foi feita a mistura das duas soluções, na proporção de 1:1, com incorporação de $2 \%$ de óleo essencial de orégano ou alecrim $(\mathrm{p} / \mathrm{v})$ e $1 \%$ de Tween 80 $(\mathrm{p} / \mathrm{v})$. Finalmente, as soluções foram homogeneizadas em Ultra-turrax (marca IKA, modelo T18, EUA) a $10.000 \mathrm{rpm}$ por $4 \mathrm{~min}$., vertidos em placas de acrílico e secos em estufa BOD (Tecnal, Brasil) over night a $25^{\circ} \mathrm{C}$. Os filmes produzidos consistiram em: controle (FC) sem adição de óleo, filme com óleo essencial de orégano (FO) e filme com óleo essencial de alecrim (FA).

\section{Extração dos compostos antioxidantes do filme}

Os filmes (1 g) foram misturados com 20 $\mathrm{mL}$ de etanol absoluto (Anidrol, Brasil) e homogeneizados a $6.000 \mathrm{rpm}$ por 15 minutos. Em seguida, a mistura foi centrifugada e o sobrenadante utilizado nas análises de compostos fenólicos totais e atividade antioxidante (ABTS e DPPH).

\section{Atividade antioxidante}

A análise antioxidante dos filmes foi realizada pelo método de DPPH e ABTS de acordo com Rufino et al ${ }^{[15]}$. Para o método de captura do radical livre DPPH, $30 \mu \mathrm{L}$ do extrato foi misturada com $3 \mathrm{~mL}$ de solução DPPH a 0,06 $\mu \mathrm{M}$ em tubos de ensaio e manteve-se em ambiente escuro por 45 minutos. A leitura das amostras foi realizada em espectrofotômetro UV-Vis (Femto, Brasil) com comprimento de onda de $518 \mathrm{~nm}$. Os resultados foram quantificados através de uma curva padrão de trolox em diferentes concentrações $\left(y=-0,0003 x+0,5632, R^{2}=\right.$ $0,999)$, e foram expressos em $\mu \mathrm{M}$ equivalente de trolox por $100 \mathrm{~g}$ de filme.

Para a determinação da atividade antioxidante pelo método ABTS ${ }^{[16]}$ inicialmente foi preparada uma solução estoque de ABTS $7 \mathrm{mM}$ e persulfato de potássio $140 \mathrm{mM}$. Para o preparo do radical ABTS $\left(\right.$ ABTS $^{+}$), $5 \mathrm{~mL}$ da solução estoque de ABTS foi misturada com 88 $\mu \mathrm{L}$ da solução de persulfato de potássio $(7 \mathrm{mM})$ e mantida em ambiente escuro, a temperatura ambiente, por 16 horas. Em seguida, diluiu-se 1 $\mathrm{mL}$ desta mistura em álcool etílico até obter uma absorbância de 0,70 \pm 0,05 a $734 \mathrm{~nm}$. Em 
tubos de ensaio uma alíquota de $30 \mu \mathrm{L}$ do extrato do filme foi misturada com 3,0 mL do radical $\mathrm{ABTS}^{++}$e a leitura da absorbânica (734 $\mathrm{nm})$ foi realizada após 6 minutos. Os resultados foram calculados utilizando-se uma curva padrão de Trolox $(\mathrm{y}=-0,0003 \mathrm{x}+0,6609$; $\left.\mathrm{R}^{2}=0,997\right)$ e expressos em $\mu \mathrm{M}$ de Trolox equivalente por $100 \mathrm{~g}$ de filme.

\section{Compostos fenólicos totais}

O conteúdo de compostos fenólicos totais foi determinado pelo método de FolinCiocalteu ${ }^{[17]}$. Em tubos de ensaio foram misturados $200 \mu \mathrm{L}$ da fração etanólica extraída do filme e $1000 \mu \mathrm{L}$ do reagente de FolinCiocalteu $(10 \%, \mathrm{v} / \mathrm{v})$. Em seguida foi adicionado $800 \mu \mathrm{L}$ da solução de carbonato de sódio $(7,5 \%, \mathrm{p} / \mathrm{v})$ e os tubos foram mantidos em ambiente escuro por 2 horas para reação. Uma amostra branco foi preparada substituindo-se o extrato por etanol. A absorbância foi medida em comprimento de onda de $765 \mathrm{~nm}$ utilizando um espectrofotômetro UV-Vis (Femto, Brasil). Uma curva padrão foi previamente preparada utilizando diferentes concentrações de ácido gálico $\left(\mathrm{y}=10,849 \mathrm{x}-0,0051 ; \mathrm{R}^{2}=0,999\right)$. O conteúdo de compostos fenólicos totais foi expresso em mg ácido gálico equivalente/ $100 \mathrm{~g}$ filme.

\section{Atividade antimicrobiana}

A atividade antimicrobiana dos filmes foi realizada pela técnica de difusão em disco de acordo com a metodologia desenvolvida pelo Clinical and Laboratory Standards Institute $(\mathrm{CLSI})^{[18]}$, e os microrganismos utilizados foram Staphylococcus aureus (ATCC 25922) e Escherichia coli (ATCC 35218). Inicialmente, as bactérias foram reativadas em tubos contendo caldo Müeller Hinton e incubadas a $35^{\circ} \mathrm{C}$ por 24 horas. Após este processo, a suspensão bacteriana foi diluída com água peptonada $0,1 \%$ $(\mathrm{p} / \mathrm{v})$ e foi comparada a turbidez do tubo com o padrão 0,5 da escala de McFarland, que corresponde a $10^{8} \mathrm{UFC} / \mathrm{mL}$. Placas de Petri contendo Ágar Müeller Hinton foram adicionadas de $0,1 \mathrm{~mL}$ de suspensão bacteriana e foi feita a semeadura com alça de Drigalsky. Os filmes foram cortados em formato de disco (diâmetro de $1,5 \mathrm{~cm}$ ) com auxílio de uma pinça e tesoura esterilizadas, e foram então depositados no centro da placa com auxílio de uma pinça estéril. Finalmente, as placas foram incubadas a $35^{\circ} \mathrm{C}$ por $24-48$ horas e observouse a formação de halo de inibição.

\section{Propriedades mecânicas}

O teste de perfuração foi feito em texturômetro (Stable Micro Systems, modelo TA X'Tplus, Inglaterra). Os corpos de provas de 20 x $20 \mathrm{~mm}$ foram fixados em suporte de acrílico e uma sonda metálica de ponta esférica, com diâmetro de $6,35 \mathrm{~mm}$, a uma velocidade de $25 \mathrm{~mm} / \mathrm{min}$ fez a perfuração das amostras ${ }^{[19]}$. Os resultados foram expressos em termos de alongamento na perfuração, que é a relação entre a distância máxima percorrida pela sonda cilíndrica na amostra ( $\mathrm{mm}$ ) e força máxima na perfuração $(\mathrm{N})$, que é a força necessária para a sonda metálica perfurar o filme.

\section{Microscopia Eletrônica de Varredura (MEV)}

A avaliação da morfologia dos filmes foi realizada em microscópio eletrônico de varredura (Philips, modelo FEI Quanta 200 Japão). As amostras fraturadas em nitrogênio líquido foram fixadas sobre stubs com fitas de carbono e recobertas com ouro em um Sputter Coater (BAL-TEC, modeloSCD-050, Balzers, Liechtenstein). Em seguida foram visualizadas em microscópio eletrônico de varredura, com potência de aceleração de $20 \mathrm{kV}$, para análise da superfície e da região de fratura. A magnitude de observação foi de 400 x para fratura e de 200 $\mathrm{x}$ para superfície. 


\section{Análise estatística}

Os resultados foram avaliados por análise de variância (ANOVA) com o auxílio do software Statistica 10 (StatSoft, EUA) e as médias dos tratamentos comparadas pelo teste de Tukey ao nível de $5 \%$ de significância $(\mathrm{p}<0,05)$.

\section{RESULTADOS E DISCUSSÃO}

O filme comestível de gelatina e quitosana (FC) apresentou-se transparente, homogêneo e sem migração aparente de glicerol na superfície. Os filmes adicionados de óleos essenciais de alecrim e orégano (FA e FO) tiveram aparência levemente opaca, boa manuseabilidade e não foi observado migração aparente de glicerol e óleo. A espessura dos filmes variou de 100 a $150 \mu \mathrm{m}$.

As imagens obtidas por MEV podem ser usadas para avaliar a homogeneidade dos componentes do filme na matriz, a estrutura de filmes e a presença de poros e rachaduras. $\mathrm{Na}$ Figura 1 encontra-se as imagens de $\mathrm{MEV}$ da superfície e fratura dos filmes produzidos. De modo geral, todas as amostras apresentaram superfície lisa, homogênea e as imagens de fratura revelaram uma estrutura compacta e sem separação de fases, indicando uma boa interação entre a gelatina e a quitosana e adequada incorporação dos óleos essenciais na matriz. É possível afirmar que a quantidade de óleo e emulsificante (Tween 80) e as condições de homogeneização foram suficientes e adequadas para emulsificar a solução filmogênica. Bonilla e Sobral ${ }^{[13]}$ observaram comportamento similar ao incorporar extrato de boldo, guaraná, alecrim e canela em filmes de gelatina e quitosana.
Figura 1. Imagens de $\mathrm{MEV}$ dos filmes de gelatina e quitosana adicionados de óleos essenciais.

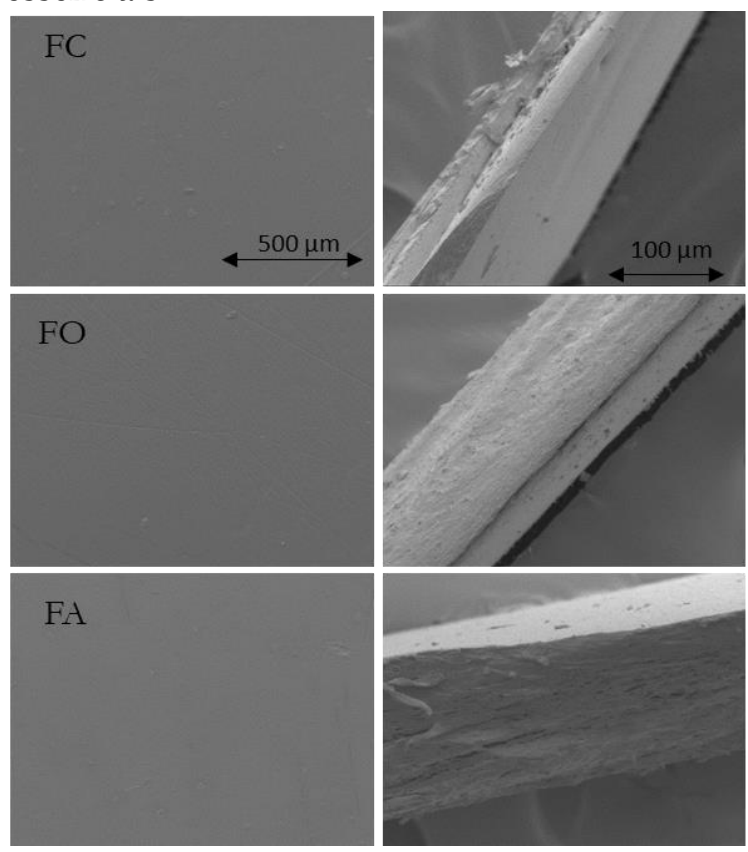

Fonte: Dados obtidos. Londrina. 2018.

A resistência do filme à perfuração é um requisito importante de embalagens plásticas para o acondicionamento de produtos alimentícios pontiagudos. Os resultados do teste de perfuração em termos de força máxima (P) e alongamento (D) na perfuração estão na Tabela 1.

Tabela 1. Propriedades mecânicas de filmes comestíveis de gelatina e quitosana contendo óleos essenciais

\begin{tabular}{cccc}
\hline Propriedade & FC & FA & FO \\
\hline $\mathrm{P}(\mathrm{N})$ & $22,0 \pm 2,5^{\mathrm{a}}$ & $34,7 \pm 2,9^{\mathrm{b}}$ & $37,9 \pm 3,5^{\mathrm{b}}$ \\
$\mathrm{D}(\mathrm{mm})$ & $3,9 \pm 0,9^{\mathrm{a}}$ & $3,7 \pm 0,4^{\mathrm{a}}$ & $4,0 \pm 0,6^{\mathrm{a}}$ \\
\hline $\mathrm{P}-$ Força máxima na perfuração & $(\mathrm{N}) ; \mathrm{D}-$ \\
alongamento na perfuração (mm). \\
a, b Médias com letras iguas na linha não \\
apresentam diferença significativa (p>0,05) pelo \\
teste de Tukey.
\end{tabular}


A adição de óleos essenciais de alecrim e orégano elevou os valores de $\mathrm{P}$, indicando que estes proporcionaram filmes mais resistentes à perfuração e não alteraram de forma significativa os valores de D. Esses resultados corroboram com as imagens de MEV apresentadas anteriormente, ou seja, filmes com microestrutura homogênea tendem a ser mais resistentes. Os filmes obtidos neste trabalho apresentaram força na perfuração superior a filmes de proteína de triticale adicionados de óleo de orégano ${ }^{[20]}$ e filmes de amido incorporados de extrato de própolis ${ }^{[21]}$.

O teor de compostos fenólicos totais e a atividade antioxidante (DPPH e ABTS) dos filmes comestíveis de gelatina e quitosana adicionados de óleos essenciais podem ser visualizados no Gráfico 1. Os filmes adicionados de óleos essenciais apresentaram compostos fenólicos, sendo em maior concentração no filme FO. Este fato fez com que o filme FO apresentasse maior atividade antioxidante, tanto pelo método ABTS como pelo DPPH. Os compostos fenólicos presentes em óleos essenciais são os principais responsáveis pela atividade antioxidante. No óleo essencial de orégano os principais compostos fenólicos encontrados são carvacrol, timol, $\gamma$-terpineno e p-cimeno e no óleo essencial de alecrim são $\alpha$-pineno, 1, 8-cineol, acetato de bornila e cânfora ${ }^{[3]}$.

A atividade antioxidante detectada no filme FC pode estar relacionada aos grupamentos amino presentes na estrutura da quitosana e da gelatina, que possivelmente reagiram com os radicais livres ${ }^{[22]}$.
Gráfico 1. Teor de compostos fenólicos totais e atividade antioxidante de filmes de gelatina e quitosana adicionados de óleos essenciais.
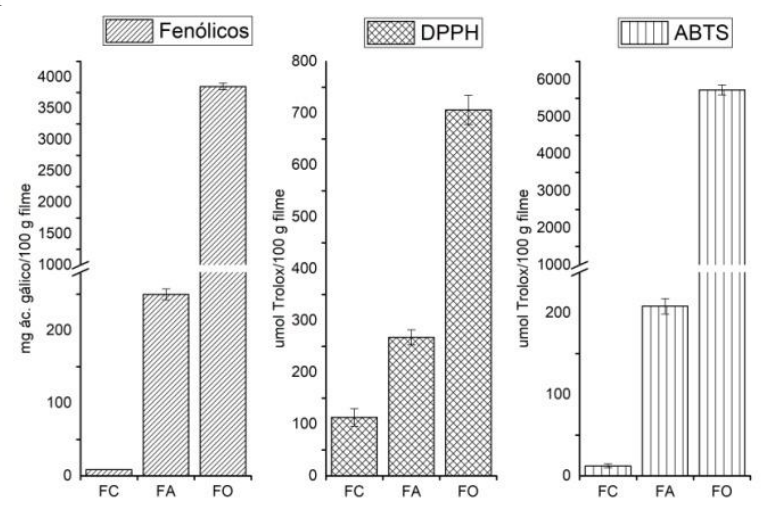

Fonte: Dados obtidos. Londrina. 2018.

Os filmes contendo óleos essenciais apresentaram atividade antimicrobiana frente a E. coli e S. aureus (Tabela 2), sendo o halo de inibição maior para o filme $\mathrm{FO}$, corroborando com os resultados de atividade antioxidante. Seydim e Sarikus ${ }^{[7]}$ também constataram que filmes de proteína do soro do leite com óleo de orégano apresentou maior capacidade antimicrobiana contra $S$. aureus, L. monocytogenes, E. coli e Lactobacillus plantarum, em comparação aos filmes contendo óleo de alecrim. De acordo com os autores, os diferentes efeitos inibitórios dos óleos essenciais podem ser atribuídos às diferenças nas propriedades biológicas dos compostos presentes no mesmo. Além disso, fatores como região de cultivo, parte da planta utilizada, preparo da matéria-prima (seca ou in natura) e metodologia de extração podem interferir na composição química dos óleos essenciais e interferir na ação antibacteriana ${ }^{[23]}$.

Em estudos similares, Hosseini et a ${ }^{[14]}$ verificaram atividade antimicrobiana de filmes de gelatina e quitosana adicionados de óleo de orégano frente a $S$. aureus, $L$. monocytogenes, $S$. enteritidis e E.coli. Bonilla e Sobral ${ }^{[13]}$ verificaram halo de inibição para $S$. aureus e E. coli em filmes de gelatina e quitosana incorporados de extrato de alecrim, canela, boldo e guaraná. 
Tabela 2. Halos de inibição de filmes comestíveis de gelatina e quitosana contendo óleos essenciais

\begin{tabular}{ccc}
\hline Filme & E. coli $(\mathrm{mm})$ & S.aureus $(\mathrm{mm})$ \\
\hline FC & 0 & 0 \\
FA & $20 \pm 1,0$ & $18 \pm 2,1$ \\
FO & $47 \pm 1,0$ & $30 \pm 3,5$ \\
\hline
\end{tabular}

Considerando o grande número de compostos químicos constituintes dos óleos essenciais, não se pode atribuir a atividade antimicrobiana e antioxidante a um mecanismo específico, podendo ter vários alvos na célula. De um modo geral, os compostos fenólicos presentes nos óleos essenciais interagem com a bicamada lipídica da membrana celular da bactéria, alteram a sua permeabilidade, causam liberação dos constituintes intracelulares vitais, impedindo a multiplicação dos microrganismos. Além disso, quando a perturbação da integridade da membrana ocorre, suas funções estão comprometidas, não apenas como uma barreira, mas também como uma matriz para enzimas e como um transdutor de energia. ${ }^{24,25,}$ 26, 27].

\section{CONCLUSÃO}

Os filmes de gelatina e quitosana apresentaram-se como uma matriz promissora para incorporação de óleos essenciais de orégano e alecrim, obtendo-se materiais com significativa atividade antioxidante e antimicrobiana. Esses filmes podem ser utilizados na fabricação de embalagens ativas, contribuindo com a segurança microbiológica, manutenção das características nutricionais e sensoriais do alimento e minimização do depósito de lixo não biodegradável no meio ambiente.

\section{AGRADECIMENTOS}

Os autores agradecem ao $\mathrm{CNPq}$ pelo auxílio financeiro (processo $n^{\circ} 445272 / 2014-7$ ) e bolsa de Iniciação Científica.

\section{REFERÊNCIAS}

[1] El Asbahani A, Miladi K, Badri W, Sala M, Ait Addi EH, Casabianca H, El Mousadik A, Hartmann D, Jilale A, Renaud FNR, Elaissari A. Essential oils: from extraction to encapsulation. International Journal of Pharmaceutics. 2015; 483: 220-243.

[2] Bakkali F, Averbeck S, Averbeck D, Idaomar M. Biological effects of essential oils - A review. Food and Chemical Toxicology. 2008; 46: 446475.

[3] Burt S. Essential oils: their antimicrobial properties and potential applications in food - a Review. International Journal of Food Microbiology. 2004; 94: 223-253.

[4] Ruiz-Navajas Y, Viuda-Martos M, Sendra E, Perez-Alvarez JA, Fernández-López J. In vitro antibacterial and antioxidant properties of chitosan edible films incorporated with Thymus moroderi or Thymus piperella essential oils. Food Control. 2013; 30: 386-392.

[5] Viuda-Martos M, El Gendy AENGS, Sendra E, Fernández-López J, Abd El Razik KA, Omer EA, Pérez-Alvarez JA. Chemical composition and antioxidant and anti-Listeria activities of essential oils obtained from some egyptian plants. Journal of Agricultural and Food Chemistry. 2010; 58: 9063-9070.

[6] Arfa AB, Chrakabandhu Y, Preziosi-Belloy L, Chalier P, Gontard N. Coating papers with soy protein isolates as inclusion matrix of carcacrol. Food Research International. 2007; 40: 22-32.

[7] Seydim AC, Sarikus G. Antimicrobial activity of whey protein based films incorporated with oregano, rosemary and garlic essential oils. Food Research International. 2006; 39: 639-644.

[8] Romani VP, Prentice-Hernandez C, Martins VG. Active and sustainable material from rice starch, fish protein and oregano essential oil for 
food packaging. Industrial Crops and Products. 2016; 97: 268-274.

[9] Gómez-Estaca J, Lacey AL, López-Caballero ME, Gómez-Guillén MC, Montero P. Biodegradable gelatin-chitosan films incorporated with essential oils as antimicrobial agents for fish preservation. Food Hydrocolloids. 2010; 27: 889896.

[10] Chiou BS, Avena-Bustillos RJ, Bechtel PJ, Jafri H, Narayan R, Imam SH, Glenn GM, Orts W. Cold water fish gelatin films: effects of crosslinking on thermal, mechanical, barrier, and biodegradable properties. European Polymer Journal. 2008; 44: 3748-3753.

[11] Abdou ES, Nagy KSA, Elsabee MZ. Extraction and characterization of chitin and chitosan from local sources. Bioresource Technology. 2008; 99: 1359-1367.

[12] Elsabee MZ, Abdou ES. Chitosan based edible films and coatings: A Review. Material Science and Engineering. 2013; 33: 1819-1841.

[13] Bonilla J, Sobral PJA. Investigation of the physicochemical, antimicrobial and antioxidant properties of gelatin-chitosan adible film mixed with plant ethanolic extracts. Food Bioscience. 2016; 16: 17-25.

[14] Hosseini SF, Rezaei M, Zandi M, Farahmandghavi F. Bio-based composite edible films containing Origanun Vulgare L. essential oil. Industrial Crops and Products. 2015; 67: 403-413.

[15] Rufino MSM, Alves RE, Brito ES, Morais SM, Sampaio CG, Pérez-Jiménez J, Saura-Calixto FD. Metodologia científica: Determinação da atividade antioxidante total em frutas pela captura do radical livre DPPH. Fortaleza: Embrapa, Comunicado técnico on line 127, 2007.

[16] Rufino MSM, Alves RE, Brito ES, Morais SM, Sampaio CG, Pérez-Jiménez J, Saura-Calixto FD. Metodologia científica: Determinação da atividade antioxidante total em frutas pela captura do radical livre ABTS. Fortaleza: Embrapa, Comunicado técnico on line 128, 2007.

[17] Singleton VL, Rossi JA. Colorimetry of total phenolics with phosphomolybdicphosphotungstic acid reagents. American Journal of Enology and Viticulture. 1965; 16: 144-158.

[18] Clinical and laboratory Standards Institute (CLSI). Performance Standards for Antimicrobial Disk Susceptibility Tests. Clinical and laboratory Standards Institute, Wayne, PA, USA. 2018; 13.

[19] Sarantópoulos CIGL, Oliveira LM, Padula M, Coltro L, Alves RMV, Garcia EEC. Propriedades mecânicas. In: Embalagens plásticas flexíveis: principais polímeros e avaliação de propriedades. Campinas: CETEA/ITAL; 2002. p. 137-177.

[20] Aguirre A, Borneo R, León AE. Antimicrobial, mechanical and barrier properties of triticale protein films incorporated with oregano essential oil. Food Bioscience. 2013; 1: 2-9.

[21] Araújo GKP, Souza SJ, Silva MV, Yamashita F, Gonçalves OH, Leimann FV, Shirai MA. Physical, antimicrobial and antioxidante properties of starch-based film containing ethanolic própolis extract. International Journal of Food Science and Technology. 2015; 50: 20802087.

[22] Yuan G, Chen X, Li D. Chitosan films and coatings containing essential oils: the antioxidant and antimicrobial activity, and application in food systems. Food Research International. 2016; 89: 117-128.

[23] Pombo, JCP Ribeiro, ER Pinto, RL Silva, BJM. Efeito antimicrobiano e sinergístico de óleos essenciais sobre bactérias contaminantes de alimentos. Segurança Alimentar e Nutricional. 2018; 25: 108-117.

[24] Skandamis PN, Nychas GJE. Effect of oregano essential oil on microbiological and 
physico-chemical attributes of minced meat stored in air and modified atmospheres. Journal of Applied Microbiology. 2001; 91: 1011 -1022.

[25] Carson CF, Mee BJ, Riley TV. Mechanism of action of Melaleuca alternifolia (tea tree) oil on Staphylococcus aureus determined by time-kill, lysis, leakage and salt tolerance assays and electron microscopy. Antimicrobial Agents and Chemotherapy. 2002; 46: 1914-1920.

[26] Porte A, Godoy RLO. Alecrim (Rosmarinus Officinalis L.): propriedades antimicrobiana e química do óleo essencial. Boletim do CEPPA. 2001; 19: 193-210.

[27] Cristiani M., D’Arrigo M., Mandalari G, Castelli F, Sarpietro MG, Micieli D. Interaction of four monoterpenes contained in essential oils with model membranes: Implications for their antibacterial activity. Journal of Agricultural and Food Chemistry. 2007; 55: 6300-6308. 